The yield of pulp was increased from 43.5 per cent to 47 . I per cent of the weight of wood used or an increase in the output of pulp from the same quantity of wood using the same quantity of cooking chemical and fuel of over 8 per cent while the quality of the pulp was improved and the bleach consumption lowered from I 3 to I I lbs. of bleaching powder per Ioo lbs. of pulp.

In seeking an explanation of this phenomenon, it was necessary to study the conditions in the digester during the cook. The consumption of caustic soda as shown in Fig. III was very rapid during the first hour and a half but constantly decreased in rate and after the second hour had reached a point where only one-fourth of the original caustic was present as such.

The condensation of steam increased very rapidly during the first hour due to the fact that the contents

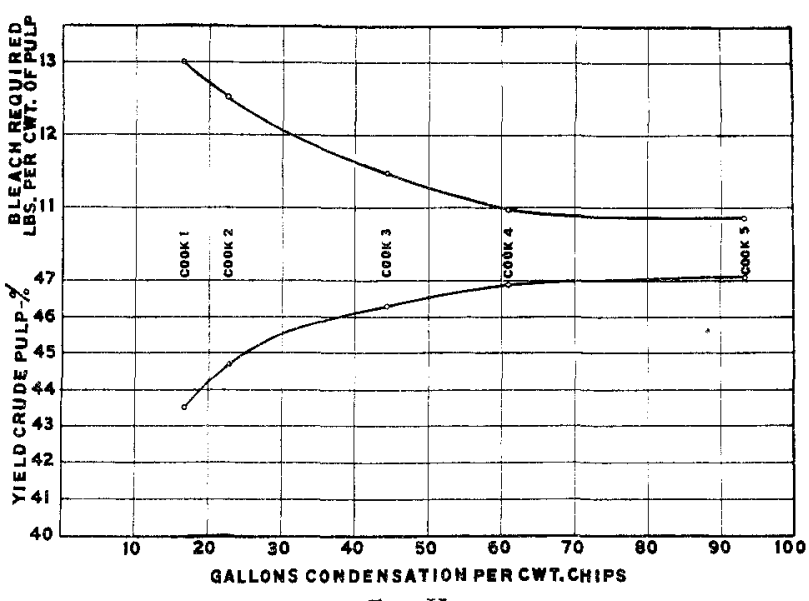

Fig. II

of the digester were being rapidly heated to the maximum temperature maintained during the succeeding 4 hrs. and the shell and lagging must necessarily be brought to the same temperature. After the first hour the rate was greatly decreased since oniy enough was needed to counteract the loss of heat through the shell and in steam vented to relieve gases and maintain circulation. The condensation for the five cooks of the series is shown graphically in Fig. IV.

During the $4 \mathrm{hrs}$. of maximum pressure, therefore, the concentrations of caustic (grams $\mathrm{NaOH}$ per liter) in the liquors were as follows:

$\begin{array}{cccccc}\text { No. } & 1 & 2 & 3 & 4 & 5 \\ \text { End of 1st hour..... } & 35 & 32 & 23 & 19 & 14 \\ \text { End of } 5 \text { th hour.... } & 6 & 7 & 5 & 4 & 3\end{array}$

With the increased condensation, the pulp reduced from the outer portion of the chips was in all probability surrounded by much more dilute liquor and was therefore, attacked much less, due to the very low adsorptive power of cellulose at those concentrations, as shown by the worls of Leighton. ${ }^{1}$

Aspen wood, on the other hand, has been found in our investigations to be capable of adsorbing at $100^{\circ}$ C. as much as 20 per cent of its weight from solutions of $60 \mathrm{~g}$. per liter and at the increased temperature of the cook the amount adsorbed would be considerably greater. Our experiments with aspen chips have shown that during the first hour of the cook the 20, 32-50. caustic soda solution has penetrated the chips at nearly the original concentration. It is evident that the uncooked inner portions of the chips are capable of adsorbing sufficient caustic soda for their reduction, but on the conversion of this material to pulp the adsorptive power is so reduced that the remaining caustic soda passes back to the liquor. The increased volume due to condensation also more effectually removes the products of reduction from the wood and decreases the contamination of the pulp therefrom.

It is evident, then, that while the power of the caustic soda to reduce the ligno-cellulose is not diminished, the attack on the pulp is considerably decreased
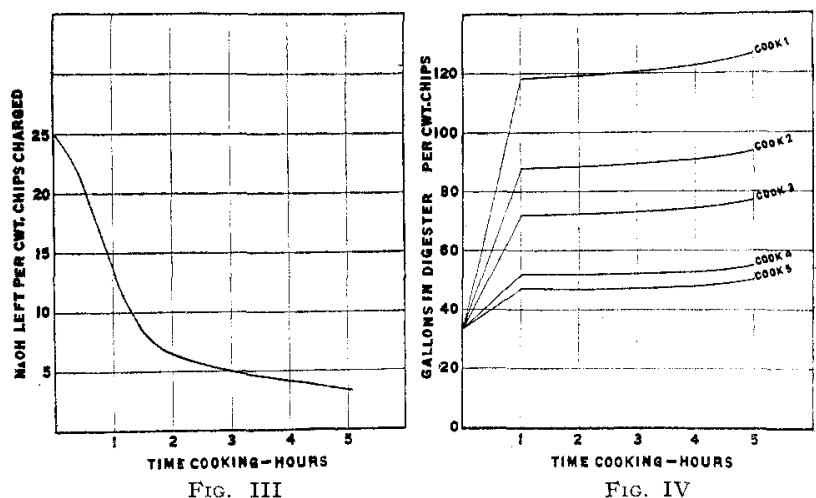

and the coloring of the pulp by the products of reduction is much less, thereby decreasing the bleach necessary to obtain a standard white. While no tests on a commercial scale have yet been tried, it seems probable that the same advantages would be gained. The equivalent of the added condensation could be obtained by injecting hot water with the steam supplied, by which means perfect control could be comparatively simple. The only disadvantage would be the increased volume of the black liquor that would have to be handled in the recovery of the soda. With multiple-effect evaporators, however, the excess water could be evaporated with very small increase in the fuel consumption and the increased production of pulp would be attained at extremely small cost.

\section{Forest Products Laboratory}

MADISON. Wiscon"SIN

\section{THE RATE OF AMMONIA DISTILLATION FROM WATER}

\section{By F. W. BRtCTMLLLER}

Received March 21, 1916

In the determination of the ammoniacal nitrogen in waters, the quantity of ammonia obtained depends upon a number of factors, principal among which are the volume of the distillate saved and the rate at which the ammonia comes over.

Regarding this matter, Wanklyn, ${ }^{1}$ the originator of the method, says:

"The recommendation has been given to nesslerize only the first $50 \mathrm{cc}$. of the free ammonia and to throw away the next I $50 \mathrm{cc}$. Formerly, it was, our custom to nesslerize all four 50 cc. tubes for the free ammonia, but that was a useless trouble, inasmuch as the first $50 \mathrm{cc}$. invariably contained three-fourths of the total free ammonia. The rule is, therefore, to nesslerize the first $50 \mathrm{cc}$. of the distillate and then add one-third. In the instance of the albuminoid ammonia, it is necessary to nesslerize each separate $50 \mathrm{cc}$, of the distillate (4) and to add the amounts together in order to arrive at the total albuminoid ammonia."

:"Water Analysis," 1896, 43. 
Mason, ${ }^{1}$ who has used the method extensively, says:

"Usually four $50 \mathrm{cc}$. tubes will be sufficient to carry off all the free ammonia, but it is the author's custom always to distil off six."

Stocks ${ }^{2}$ says:

"In distilling ordinary waters, practically the whole of the ammonia will be present in the first Ioo cc., but with sewages the whole of the ammonia may not have been obtained even after distilling $300 \mathrm{cc}$, and it is, therefore, necessary in such cases to allow the retort to cool, make up to the original volume with distilled water and continue the distillation. The albuminoid ammonia being formed by the oxidation of organic matter, is not evolved so quickly as the free ammonia, hence it may be necessary to distil several Ioo cc. portions before it ceases to be evolved."

"The "Standard Methods of Water Analysis" (I9I2 Edition) recommends the collection of three $50 \mathrm{cc}$. portions for the free ammonia, and at least four, preferably five, $50 \mathrm{cc}$. portions for albuminoid ammonia. This procedure we were using until we saw an advance copy of the Revision of the Standard Methods and learned that it was recommending a collection of four $50 \mathrm{cc}$. Nessler tubes in the distillation of the free ammonia and five in the case of albuminoid ammonia.

In order to see what influence this procedure would have upon the results obtained, we began a statistical study of the quantities of ammonia collected in each tube, as well as the total amount obtained. The results of this study are herein contained.

We have been following the revised procedure for several months, using it on all classes of water. The total number of waters examined was between 500 and I000; the free ammonia varied from 0.002 to 2.0 parts per million, and the albuminoid from 0.002 to 4. 0 parts per million. A compilation of all of the results, with regard to amount and rate of ammonia distilling, were made and the conclusions obtained were as follows

Nitrogen As FreE Ammonia

Fourth tube averages 5 per cent of the total nitrogen

76 per cent of the waters had 100 per cent nitrogen in 3 tubes

24 per cent of the waters had 95 per cent nitrogen in 3 tubes

50 per cent of the waters had 50 to 55 per cent nitrogen in 1 tube
20 per cent of the waters had 65 to 70 per cent nitrogen in 1 tube Nitrogen as AlBuminom AMmonia

Fifth tube averages 5 per cent of the total nitrogen

75 per cent of the waters had 100 per cent nitrogen in 4 tubes
25 per cent of the waters had 95 per cent nitrogen in 4 tubes

30 per cent of the waters had 50 to 60 per cent nitrogen in 1 tube
20 per cent of the waters had 60 to 70 per cent nitrogen in 1 tube

Those waters which had 5 per cent of the nitrogen in the last tube had a total nitrogen content of either free or albuminoid ammonia of $I$ part per million or more of nitrogen. Since ordinary waters, unless grossly polluted, contain less than I part per million of nitrogen as free or albuminoid ammonia, we can conclude that the collection of a $4^{\text {th }}$ tube in the free ammonia determination and $a^{\text {th }}$ in the albuminoid determination, under ordinary circumstances, is not necessary. Furthermore, the average per cent found in the last tube, including all samples, was only 5 per cent of the total nitrogen.

In a water containing less than I part per million the maximum error is 0.05 part per million; in a water containing 4 parts per million, the maximum amount found in the waters examined, the error is 0.2 part per million. In other words, in one case we would report $0.95 \mathrm{p}$. p. m. of nitrogen and in the other 3.80 .

I "Examination of Water," 1913, 62.

? "Water Analysis," 1912, 11 .
However, since the ammonia determination is not quantitative and the results are used only as a basis for determining pollution, the question to be decided is whether or not the error of $0.05 \mathrm{p} . \mathrm{p} . \mathrm{m}$. in one case and 0.2 in the other, would cause a change of judgment. We think it would not; that is, a water with I p. p. m. of nitrogen would stand as good a chance of being condemned as one containing 0.95 p. p. m., if all the other evidences pointed towards contamination.

We conclude, therefore, from this study that in order to get sufficient information upon which to base a judgment, it is not necessary, in ordinary routine water analysis, to nesslerize more than three $50 \mathrm{cc}$. portions for free ammonia, and four $50 \mathrm{cc}$. portions for albuminoid ammonia.

\footnotetext{
WATER and Sewage Laboratory
}

UNIVERSTTY OF KANSAS, LAWRENCE

\section{A MODIFICATION OF MCCRUDDEN'S METHOD FOR \\ CALCIUM, FOR THE ESTIMATION OF CALCIUM AND STRONTIUM IN THE PRESENCE OF PHOSPHORIC ACID AND A SMALL AMOUNT OF IRON}

BY 0 . B. WINTER

Received August 11, 1915

The method ${ }^{1}$ generally used in estimating calcium and strontium, when both are present in a solution, is to precipitate them as the oxalates, burn to the oxides, change to the nitrates, separate the calcium nitrate from the strontium nitrate by means of absolute alcohol and ether, and then determine each element separately. If phosphoric acid and iron are also present in the solution with the calcium and strontium salts, the separation becomes much more difficult since calcium, strontium and iron phosphates are quite insoluble in a neutral or alkaline solution. In this latter case, the phosphoric acid and iron are removed before the calcium and strontium are determined. This is usually accomplished by precipitating ${ }^{2}$ the phosphoric acid as ferric phosphate, and the excess of iron as ferric subacetate. However, when there is a large amount of phosphoric acid in the solution, this method becomes tedious because the bulky, gelatinous precipitate formed causes the solution to filter very slowly, and it is almost impossible to wash all of the calcium and strontium salts out of this precipitate.

McCrudden has worked out a method" for "The quantitative separation of calcittm and magnesium in the presence of phosphoric acid and small amounts of iron, devised especially for the analysis of foods, urine and feces." By this method the calcium is precipitated very slowly as the oxalate in a boiling solution containing a small amount of free hydrochloric acid. This gives rise to a condition in which the calcium oxalate comes down very coarsely crystalline, and apparently no soluble salts are carried down by occlusion.

The above method was found accurate for the estimation of calcium, but in trying it out on a strontium

1 U. S. Dept. of Agr., Bureau of Chemistry, Bull. 162, 44.

"Perkin, "Methods in Qual, Analysis." p. 76

J. Biol. Chem. 7 (1909), 83. 